\title{
Fine-scale Genetic Population Structure of Chum Salmon on the Iwate Coast, Northern Japan
}

\author{
Shino Kitamura ${ }^{1}$, Tomoaki Goto ${ }^{1}$, Hideharu Tsukagoshi ${ }^{1}$, Yu-ichi Shimizu ${ }^{2}$, Fumihisa Takahashi ${ }^{3}$, and Syuiti \\ Abe $^{1}$
}

${ }^{I}$ Sanriku Fisheries Research Center, Iwate University, Iwate, Japan

${ }^{2}$ Iwate Fisheries Technology Center, Iwate, Japan

${ }^{3}$ Fisheries Resources Institute, Japan Fisheries Research and Education Agency, Iwate, Japan

Keywords: fine-scale genetic population analysis, chum salmon, Iwate coastal rivers

\section{Background and Objectives}

Chum salmon (Oncorhynchus keta), with a wide natural range from the Far East to North America and high commercial importance in North Pacific fisheries (Salo 1991), is also an important fishery species in northern Japan. However, the chum salmon catch, or homing number, has been decreasing for nearly two decades on the coast of Iwate Prefecture or the Sanriku-region - the exact reason for such a decrease remains obscure. For effective conservation and management of a species, an accurate description of the genetic population structure is necessary (Spruell et al. 1999) to help provide a clear understanding of what constitutes a population and how population boundaries vary among different watersheds (DeHaan et al. 2014). Two salmon homing peaks are known in Iwate: an early-run from September to the end of October, and late-run from November to February. For conservation and fisheries management of chum salmon in Iwate, the temporal fine-scale genetic population structure was examined using fish collected from the Tsugaruishi River (TGI, predominantly late-run) and Akka River (AKA, predominantly early-run) through the entire homing season.

\section{Materials and Methods}

Dorsal fin samples from a total of 2,089 fish (TGI: 10 collections 902 individuals, AKA: 12 collections 1,187 individuals) were collected during the homing seasons, September 2018 to January 2019 (see Fig. 1 for locations). The samples were coded every ten days in each month: 1 to 10 as early (E), 11 to 20 as middle (M), and 21 to the end of the month as late (L). All fin samples were fixed in $85 \%$ ethanol and stored at room temperature until DNA extraction. Total genomic DNA was extracted with the Gentra Puregene Tissue Kit (QIAGEN) following the manufacturer's protocol.

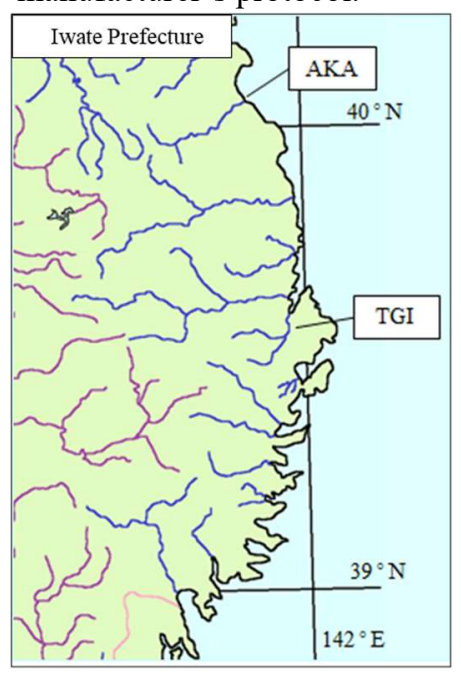

Fig. 1. Location of the Tsugaruishi (TGI) and Akka (AKA) rivers.

For the genetic analyses, 14 polymorphic microsatellite (ms) DNA loci (Tsukagoshi et al. 2015, partially unpublished) were used. To estimate genetic variability, the number of alleles $(\mathrm{Na})$, allelic richness $(\mathrm{Ar})$, and the expected $(\mathrm{He})$ and observed heterozygosities $(H \mathrm{O})$ were calculated with the FSTAT (Goudet 2003) and Arlequin ver. 3.5 (Excoffier and Lischer 2010) programs. For genetic population structure, pairwise $F_{\text {ST }}$ estimate, STRUCTURE, Principal Coordinate Analysis (PCoA), molecular phylogenetic Neighbor-joining (NJ) tree using CSE genetic distances (Cavalli-Sforza and Edwards 1967), and AMOVA were performed using the above Arlequin ver. 3.5, 
AMOVA, STRUCTURE 2.3.4 (Pritchard et al. 2000), GenAlex 6.51b2 (Peakall and Smouse 2012), and PHYLIP (Felsenstein 2004) programs.

\section{Results}

The mean Na per collection for TGI and AKA was 14.14 (10L) to $15.42(11 \mathrm{M})$, and 14.64 (11E) to 15.92 (9E and 9L), respectively, and the value of early-run in AKA was higher than in the late-run (Mann-Whitney $\mathrm{U}$ test, $p<$ 0.01). The mean $A \mathrm{r}$ per collection for TGI and AKA was found to be from 13.40 (12L) to 15.07 (10E), and 13.60 (11E) to 14.95 (9E), respectively, and the value of early-run in AKA was higher than in the late-run (Mann-Whitney $\mathrm{U}$ test, $p<0.01)$. The mean $H \mathrm{e}$ per collection for TGI and AKA was $0.835(12 \mathrm{~L})$ to $0.859(10 \mathrm{E})$, and 0.834 (11E) to $0.859(9 \mathrm{E}$ and $9 \mathrm{M})$, respectively, and the Mann-Whitney $\mathrm{U}$ test between early-run and late-run was not significant in both TGI and AKA $(p>0.05)$. The mean Ho per collection for TGI and AKA was $0.818(12 \mathrm{~L})$ to $0.859(10 \mathrm{E})$, and 0.824 (12E) to 0.853 (10L), respectively, and the Mann-Whitney $\mathrm{U}$ test between early-run and late-run was significant in AKA $(p<0.05)$ but not in TGI $(p>0.05)$. A statistically significant deviation from HWE was not observed in all collections at $14 \mathrm{msDNA}$ loci with Bonferroni corrections $(p>0.05 / 14=0.00357)$.

Pairwise $F_{\text {ST }}$ estimates (Table 1) suggested a significant difference between the early-run and late-run in both TGI and AKA, within rivers and also between rivers, after Bonferroni corrections $(p<0.01)$ and AMOVA $(p<$ $0.001)$. In addition, moderate gene flow estimated by pairwise $F_{\mathrm{ST}}$ was inferred within the early-run and the late-run groups of TGI and the late-run group of AKA.

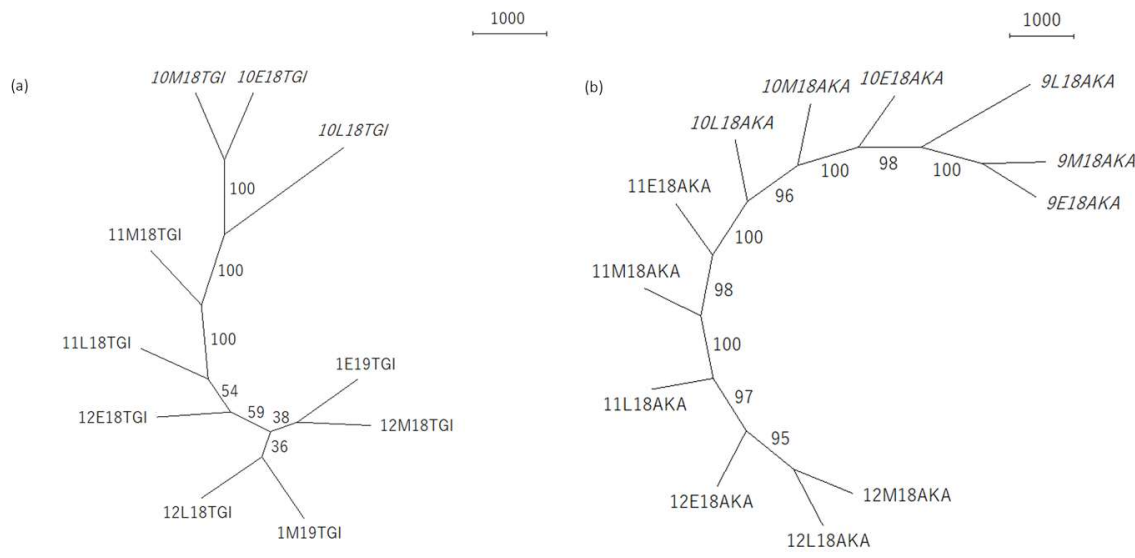

Fig. 2. NJ tree for TGI (a) and AKA (b). Early-run collections in italic.

NJ trees (Fig. 2) also suggested genetic differentiation between early- and late-run with 100\% support, and a closer kinship between the neighboring than the distant collections in both early- and late-runs of TGI and AKA. Such differentiation between early- and late-run collections in both rivers was favored by the results of STRUCTURE with $\triangle \mathrm{K}(K=2)$ and PCoA (not shown).

\section{Conclusions}

The present study showed temporal genetic differentiation and structure using 14 msDNA loci in two representative rivers with different homing peaks, TGI and AKA, in Iwate. The obtained findings suggest distinct temporal reproductive isolation between the early- and late-run of chum salmon in both rivers. A moderate gene flow inferred within temporal homing groups in each river may indicate past anthropogenic activity such as artificial transplantation between rivers. The present findings suggest the usefulness of temporal fine-scale analysis through the entire season for unraveling complex salmon homing dynamics. Further studies will provide the basic information for conservation and management for sustainable use of chum salmon resources in Iwate.

Acknowledgments - We thank Tsugaruishi Sake-Masu Salmon Hatchery, Miyako Fisheries Cooperative Association, Iwate, Japan, and Shimo-Akka Salmon Hatchery, Shimo-Akka Fisheries Cooperative Association, Iwate, Japan, for kindly providing samples used. 
Table 1. The results of $F_{\mathrm{ST}}$ analysis ( $* p<0.05$ after Bonferroni correction). Early-run collections in italic.

\begin{tabular}{|c|c|c|c|c|c|c|c|c|c|c|c|c|c|c|c|c|c|c|c|c|c|c|}
\hline & & \multicolumn{10}{|l|}{ TGI } & \multicolumn{11}{|l|}{ AKA } \\
\hline & & $10 E 18$ & $10 \mathrm{MI8}$ & $10 L 18$ & $11 \mathrm{M} 18$ & 11L18 & $12 \mathrm{E} 18$ & $12 \mathrm{M} 18$ & $12 \mathrm{~L} 18$ & 1E19 & $1 \mathrm{M} 19$ & $9 E 18$ & $9 M 18$ & 9L18 & $10 E 18$ & I0M18 & $10 L 18$ & $11 E 18$ & $11 \mathrm{M} 18$ & $11 \mathrm{~L} 18$ & $12 \mathrm{E} 18$ & $12 \mathrm{M} 18$ \\
\hline \multirow[t]{8}{*}{ TGI } & $\begin{array}{l}10 E 18 \\
10 M 18 \\
10 L 18\end{array}$ & $\begin{array}{c}- \\
0.00189 \\
*_{0} 0.00690\end{array}$ & $\begin{array}{c}- \\
0.00224\end{array}$ & & & & & & & & & & & & & & & & & & & \\
\hline & $11 \mathrm{M} 18$ & ${ }^{*} 0.00822$ & $*_{0.00401}$ & 0.00174 & - & & & & & & & & & & & & & & & & & \\
\hline & $11 \mathrm{~L} 18$ & ${ }^{*} 0.01570$ & $*_{0.00921}$ & ${ }^{*} 0.00641$ & 0.00033 & - & & & & & & & & & & & & & & & & \\
\hline & $12 \mathrm{E} 18$ & ${ }^{*} 0.01662$ & ${ }^{*} 0.00969$ & ${ }^{*} 0.00595$ & 0.00090 & -0.00020 & - & & & & & & & & & & & & & & & \\
\hline & $12 \mathrm{M} 18$ & ${ }^{*} 0.01532$ & $*_{0.00907}$ & $*^{*} .00569$ & 0.00060 & 0.00064 & -0.00030 & - & & & & & & & & & & & & & & \\
\hline & $12 \mathrm{~L} 18$ & ${ }^{*} 0.01908$ & $*_{0.01256}$ & ${ }^{*} *_{0.00835}$ & ${ }^{*} 0.00219$ & -0.00024 & 0.00055 & 0.00005 & - & & & & & & & & & & & & & \\
\hline & $1 \mathrm{E} 19$ & ${ }^{*} 0.01721$ & $*_{0.01060}$ & ${ }^{*} 0.00672$ & ${ }^{*} 0.00169$ & 0.00035 & 0.00008 & -0.00006 & -0.00027 & - & & & & & & & & & & & & \\
\hline & 1M19 & ${ }^{*} 0.01823$ & $*_{0.01278}$ & ${ }^{*}{ }_{0.00880}$ & ${ }^{*} 0.00428$ & 0.00123 & 0.00043 & 0.00220 & 0.00099 & 0.00025 & - & & & & & & & & & & & \\
\hline \multirow[t]{12}{*}{ AKA } & $9 E 18$ & 0.00186 & $*_{0.00431}$ & ${ }^{* *_{0.00870}}$ & ${ }^{*} 0.01254$ & $*_{0.01933}$ & $*_{0.02018}$ & ${ }^{*} *_{0.01830}$ & $*_{0.02294}$ & $*_{0.02013}$ & $*_{0.02191}$ & - & & & & & & & & & & \\
\hline & $9 M 18$ & 0.00183 & $*_{0.00506}$ & ${ }^{*}{ }_{0.00810}$ & ${ }^{*} 0.01135$ & $* 0.01806$ & ${ }^{*} 0.01947$ & $*_{0.01793}$ & $*_{0.02110}$ & $*_{0.01911}$ & $*_{0.02066}$ & -0.00079 & - & & & & & & & & & \\
\hline & $9 L 18$ & 0.00175 & 0.00151 & $*^{*} .00350$ & ${ }^{*} 0.00516$ & $*_{0.01076}$ & ${ }^{*} 0.01249$ & $*_{0.01115}$ & $*^{*} 0.01398$ & $*_{0.01175}$ & $*_{0.01377}$ & ${ }^{*} 0.00191$ & 0.00079 & - & & & & & & & & \\
\hline & $10 E 18$ & 0.00139 & 0.00104 & 0.00163 & ${ }^{*} 0.00553$ & $*_{0.01106}$ & ${ }^{*} 0.01190$ & $* 0.01165$ & $*_{0.01424}$ & $*_{0.01274}$ & $*_{0.01392}$ & ${ }^{*} 0.00505$ & $*_{0.00497}$ & 0.00100 & - & & & & & & & \\
\hline & $10 M 18$ & $*^{*} 0.00466$ & 0.00137 & 0.00048 & ${ }^{*} 0.00310$ & ${ }^{*} 0.00924$ & ${ }^{*} 0.00936$ & $*_{0.00953}$ & $*_{0.01150}$ & $*_{0.01126}$ & $*_{0.01256}$ & $*_{0.00689}$ & ${ }^{*} 0.00702$ & $*^{*} 0.00171$ & 0.00099 & - & & & & & & \\
\hline & $10 L 18$ & ${ }^{*} 0.00867$ & ${ }^{*} 0.00367$ & 0.00094 & ${ }^{*} 0.00229$ & ${ }^{*} 0.00705$ & ${ }^{*} 0.00645$ & ${ }^{*} 0.00787$ & ${ }^{*} 0.00909$ & ${ }^{*} 0.00849$ & ${ }^{*} 0.01069$ & ${ }^{*} 0.01106$ & ${ }^{*} 0.01127$ & ${ }^{*} 0.00445$ & ${ }^{*} 0.00428$ & -0.00028 & - & & & & & \\
\hline & $11 \mathrm{E} 18$ & ${ }^{*} 0.01334$ & $*_{0.00878}$ & 0.00302 & ${ }^{*} 0.00291$ & $*^{*} 0.00579$ & $*^{*} 0.00582$ & $*_{0.00619}$ & $*^{*} 0.00729$ & $*_{0.00654}$ & ${ }^{*} 0.00878$ & $*_{0.01686}$ & $*_{0.01741}$ & $* 0.00782$ & $* 0.00762$ & $*_{0.00297}$ & 0.00105 & - & & & & \\
\hline & $11 \mathrm{M} 18$ & $*^{*} 0.01166$ & $* 0.00567$ & 0.00261 & 0.00099 & ${ }^{*} 0.00373$ & ${ }^{*} 0.00346$ & ${ }^{*} 0.00298$ & $* 0.00450$ & ${ }^{*} 0.00453$ & ${ }^{*} 0.00650$ & ${ }^{*} 0.01615$ & ${ }^{*} 0.01489$ & ${ }^{*} 0.00644$ & ${ }^{*} 0.00746$ & ${ }^{*} 0.00270$ & 0.00086 & -0.00054 & & & & \\
\hline & $11 \mathrm{~L} 18$ & $*_{0.01435}$ & $*_{0.00756}$ & $*_{0.00416}$ & 0.00127 & 0.00163 & 0.00189 & 0.00187 & 0.00173 & 0.00268 & $*_{0.00438}$ & $*_{0.01868}$ & $*_{0.01815}$ & $*_{0.00948}$ & $*_{0.00948}$ & $*_{0.00578}$ & $* 0.00311$ & $*_{0.00225}$ & 0.00011 & - & & \\
\hline & $12 \mathrm{E} 18$ & $*^{*} 0.01838$ & $*^{*} 0.01082$ & ${ }^{*} 0.00599$ & 0.00107 & 0.00090 & -0.00018 & -0.00009 & 0.00141 & 0.00012 & $*_{0.00254}$ & $*^{*} 0.02157$ & $*_{0.02156}$ & ${ }^{*} 0.01344$ & $*_{0.01296}$ & ${ }^{*} 0.00964$ & ${ }^{*} 0.00648$ & ${ }^{*} 0.00515$ & $*^{*} 0.00345$ & 0.00123 & - & \\
\hline & $12 \mathrm{M} 18$ & $*_{0.01769}$ & $*_{0.01059}$ & $*_{0.00617}$ & 0.00128 & 0.00049 & 0.00038 & 0.00088 & -0.00068 & 0.00046 & 0.00192 & $*^{*} 0.02052$ & $*_{0.01930}$ & $*_{0.01137}$ & $*_{0.01245}$ & ${ }^{*} 0.00924$ & $* 0.00624$ & $*^{*} 0.00500$ & $*_{0.00321}$ & 0.00143 & 0.00112 & - \\
\hline & $12 \mathrm{~L} 18$ & ${ }^{*} 0.01579$ & ${ }^{*} 0.01007$ & ${ }^{*} 0.00555$ & 0.00036 & -0.00015 & 0.00065 & -0.00067 & -0.00075 & -0.00079 & 0.00054 & ${ }^{*} 0.01948$ & ${ }^{*} 0.01806$ & ${ }^{*} 0.01117$ & $*^{*} 0.01157$ & ${ }^{*} 0.00939$ & ${ }^{*} 0.00734$ & ${ }^{*} 0.00536$ & ${ }^{*} 0.00287$ & 0.00109 & 0.00094 & -0.00089 \\
\hline
\end{tabular}




\section{REFERENCES}

Cavalli-Sforza, L.L., and A.W. Edwards. 1967. Phylogenetic analysis. Models and estimation procedures. Am. J. Hum. Genet. 19: 233-257.

DeHaan, P., B. Adams, and M.C. Nelson. 2014. Fine-scale population structure analysis and genetic population assignments of Wenatchee River sub-basin bull trout. Abernathy Fish Technology Center Final Report. 45pp.

Excoffier, L., and H.E.L. Lischer. 2010. Arlequin suite ver. 3.5: a new series of programs to perform population genetics analyses under Linux and Windows. Mol. Ecol. Resour. 10: 564-567.

Felsenstein, J. 2004. PHYLIP (Phylogeny Inference Package) version 3.6. Distributed by the author. Department of Genome Sciences, Univ. Washington, Seattle.

Goudet, J. 2003. FSTAT (ver. 2.9.4), A program to estimate and test population genetics parameters. Updated from Goudet [1995]. (Available from https://www2.unil.ch/popgen/softwares/fstat.htm)

Peakall, R, and P.E. Smouse. 2012. GenAlEx 6.5: genetic analysis in Excel. Population genetic software for teaching and research - an update. Bioinformatics 28: 2537-2539.

Pritchard, J.K., M. Stephens, and P. Donnelly. 2000. Inference of population structure using multilocus genotype data. Genetics 155: 945-959.

Salo, E.O. 1991. Life history of chum salmon (Oncorhynchus keta). In Pacific salmon life histories. Edited by C. Groot and L. Margolis. Univ. British Columbia Press, Vancouver. pp. 231-309.

Spruell, P., B.E. Rieman, K.L. Knudsen, F.M. Utter, and F.W. Allendorf. 1999. Genetic population structure within streams: microsatellite analysis of bull trout populations. Ecol. Freshw. Fish 8: 114-121.

Tsukagoshi, H., S. Terui, and S. Abe. 2015. Characterization of sixteen polymorphic microsatellite DNA loci in the chum salmon (Oncorhynchus keta) isolated by next-generation sequencing. Conserv. Genet. Resour. 7: 173175 . 